\title{
Parents' perceptions of the gluten-free casein-free diet for their children with autism
}

\author{
Annette Puglisi \\ West Virginia University
}

Follow this and additional works at: https://researchrepository.wvu.edu/etd

\section{Recommended Citation}

Puglisi, Annette, "Parents' perceptions of the gluten-free casein-free diet for their children with autism" (2005). Graduate Theses, Dissertations, and Problem Reports. 2222.

https://researchrepository.wvu.edu/etd/2222

This Thesis is protected by copyright and/or related rights. It has been brought to you by the The Research Repository @ WVU with permission from the rights-holder(s). You are free to use this Thesis in any way that is permitted by the copyright and related rights legislation that applies to your use. For other uses you must obtain permission from the rights-holder(s) directly, unless additional rights are indicated by a Creative Commons license in the record and/ or on the work itself. This Thesis has been accepted for inclusion in WVU Graduate Theses, Dissertations, and Problem Reports collection by an authorized administrator of The Research Repository @ WVU. For more information, please contact researchrepository@mail.wvu.edu. 


\title{
PARENTS' PERCEPTIONS OF THE GLUTEN-FREE CASEIN-FREE DIET
} FOR THEIR CHILDREN WITH AUTISM

\author{
Annette Puglisi \\ Thesis submitted to the College of Agriculture \& Forestry \\ at \\ West Virginia University \\ in partial fulfillment of the requirements \\ for the degree of \\ Master of Science \\ in \\ Human Nutrition and Foods \\ Cindy Fitch, Ph.D., R.D., L.D. Chair \\ Monica Andis, M.S., R.D., LD. \\ Erron Huey, Ph.D. \\ Division of Family \& Consumer Sciences
}

Morgantown, West Virginia

2005

Keywords: autism, dietary restrictions, elimination diet, nutrition 


\title{
ABSTRACT \\ PARENTS' PERCEPTIONS OF THE GLUTEN-FREE CASEIN-FREE DIET FOR THEIR CHILDREN WITH AUTISM
}

\begin{abstract}
Annette Puglisi
This study surveyed some of the factors influencing parents' decisions to put their children with autism on a gluten free, casein free diet (gfcf diet). Parents completed a fifteen question survey about their motivations for trying the diet and how the diet affected their lives. In addition, parents were asked to fill out three day diet histories of what their children were eating, for nutrient analysis.

Fifty three surveys (21\%) and ten diet histories were returned. A majority of parents (60\%) learned about the gfcf diet from the Internet (28\%) or from Parent Magazine (32\%). Twenty-five percent of parents cited desperation as their main reason for trying the diet. Forty-seven percent reported having their children on the diet for three years or more, while $92 \%$ reported that they had eliminated additional nutrients besides gluten and casein from their children's diets. Thirty-nine percent reported that the diet was hard to implement and maintain, but only at first. Traveling/eating out was cited as the most difficult part of maintaining the diet. Speech therapy was the most common therapy children were receiving besides the gfcf diet. While $71 \%$ of parents said that they had consulted a health care professional for assistance in implementing the diet, these consultations took place over the Internet with practitioners who may not have been licensed health professionals. Overall, 57\% of parent felt the behavioral changes that they had seen in their children were due to the gluten free casein free diet.
\end{abstract}




\section{ACKNOWLEDGEMENTS}

I extend my sincere appreciation to Monica Andis, mentor, committee member,

and friend, for many hours of assistance and revisions. She has also provided guidance in the field of nutrition.

I thank Dr. Cindy Fitch for her time and patience as committee chair and graduate advisor. Her advice over the past six years has led me in the right direction.

I thank Dr. Erron Huey for agreeing to be a committee member. He added a great deal of knowledge and patience.

To my parents, Charles and Margaret Puglisi for their many words of encouragement, I extend my love and gratitude.

To my brothers, Jake and Doug Puglisi, I thank you for kind words and comic relief through a long process.

To my fiancé, Gary Freshour, for your time, patience, love, and encouragement, I extend my gratitude and my love for both of our lifetimes.

Last, I would like to thank all of the parents who took the time to fill out my survey. 


\section{Table of Contents}

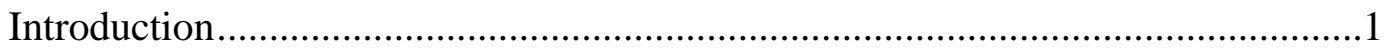

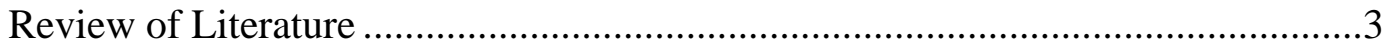

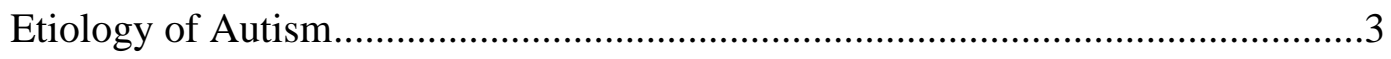

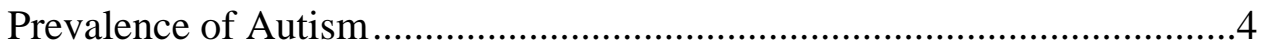

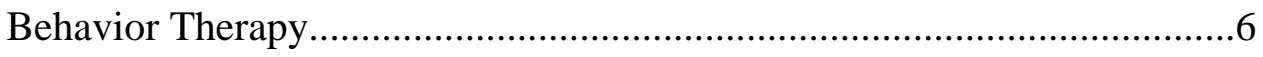

Treatment- Nutritional Therapies ....................................................

Diet Therapy ...........................................................................

Opioid Excess Theory ..................................................................

Statement of the Problem....................................................................15

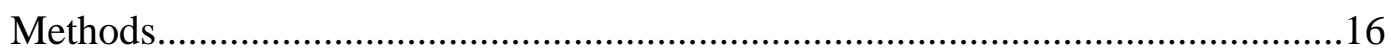

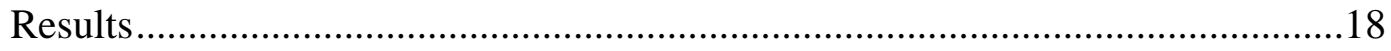

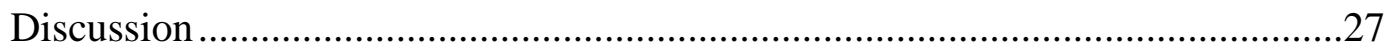

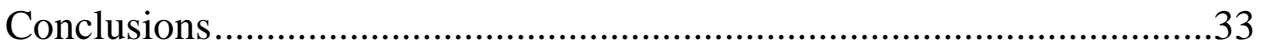

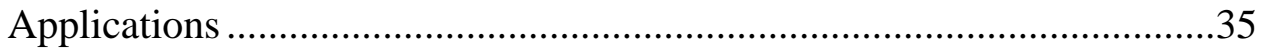

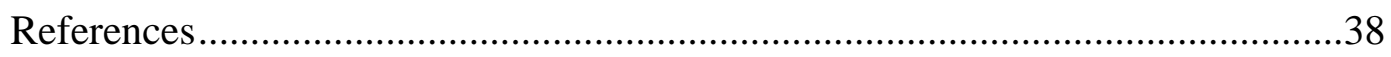

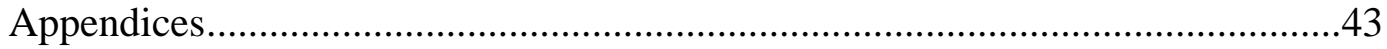

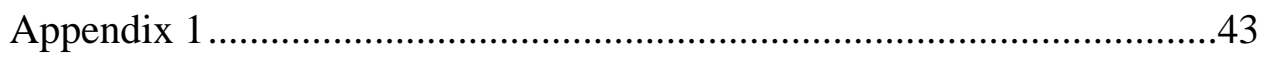

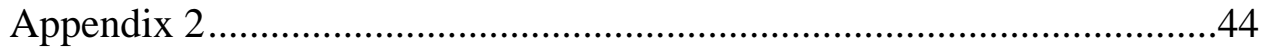

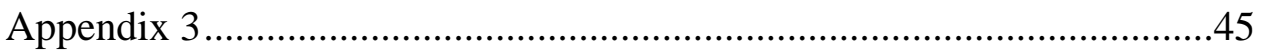

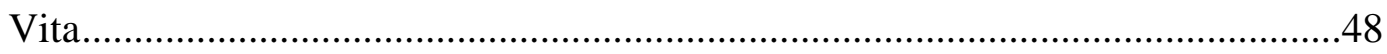




\section{List of Tables}

TABLE 1: Parents' initial source of information about the gfcf diet ....................18

TABLE 2: Motivating factors to try the gfcf diet............................................19

TABLE 3: Length of time children were/are on the diet ...................................20

TABLE 4: What foods were eliminated ........................................................20

TABLE 5: Of the foods eliminated, which ones did your child like ....................21

TABLE 6: Difficulties maintaining the gfcf diet..............................................22

TABLE 7: Behavioral changes reported by parents/Number of parents who believed improvement was solely due to the gfcf diet......................................23

TABLE 8: Other therapies children received in addition to the gfcf diet..............24

TABLE 9: Consultations with health care professionals concerning the

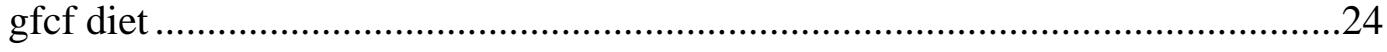

TABLE 10: Parent's belief about their children receiving a balanced diet while on

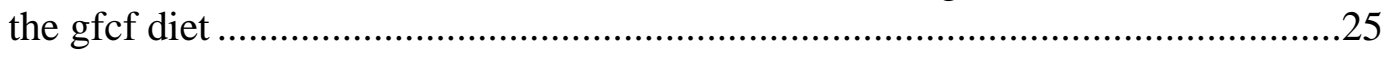

TABLE 11: Supplements used by parents .....................................................26

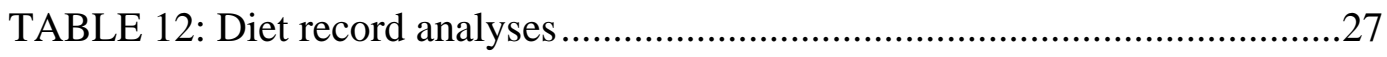




\section{Introduction}

Autism is characterized by a qualitative impairment in verbal and nonverbal communication, in imaginative activity, and in reciprocal social interaction. Among the most notable symptoms and signs are: under or poorly developed verbal and nonverbal communication skills, abnormalities in speech patterns, impaired ability to sustain a conversation, abnormal social play, lack of empathy, and an inability to make friends. Frequently, these are accompanied by stereotypical body movements, a marked need for sameness, very narrow interests, and a preoccupation with parts of the body (Travarthen 1996).

Autism was first described in 1943 by Leo Kanner. He described the main characteristics of the condition as: 1) an inability to establish social relatedness, 2) a failure to use language normally for the purpose of communication, 3) an obsessive desire for the maintenance of sameness, 4) a fascination for objects, and 5) good cognitive potentialities. Additionally, onset of these characteristics tend to appear in children before the age of 30 months (Travarthen 1996).

Behaviorally, the child with autism is withdrawn and often spends hours in solitary play. Eye contact is minimal or absent. Further manifestations appear in visual scanning of hand and finger movements, mouthing of objects, and rubbing of surfaces may indicate a heightened awareness and sensitivity to other stimuli, whereas diminished responses to pain and lack of startle responses to sudden loud noises reflect lowered sensitivity to other stimuli. If speech is present, echolalia, pronominal reversal, nonsense rhyming and other idiosyncratic language forms may predominate. Ritualistic behavior 
prevails reflecting the child's need to maintain a consistent, predictable environment. Tantrum-like rages may accompany disruptions of routine. (Dalton 2000).

A significant number of children with autism may also have food selectivity. Food selectivity is the voluntary restriction of food from the diet. Prevalence of food selectivity in the ASD population is estimated to range from 30-50\%; however, in one survey, $90 \%$ of families interviewed reported mealtime difficulties. (Ahearn et al, 2001). Food selective children may avoid all smooth foods, all crunchy foods, one or more entire food groups, or eat no more than 3- 5 foods altogether (CED Feeding \& Swallowing Clinic). Theories as to what causes children with ASD to be food selective include: obsessive desire for order, obsession for familiarity, increased oral sensitivities, limited tolerance for change, altered visual perceptions (Isherwood and Thomas, 2003). Changing dietary habits of children with food selectivity is very difficult. (Kedesdy and Budd, 1998)

There are many theories about how autism is caused. Early theories include negative interactions with parents, maternal deprivation, or even emotional stress originally suffered by the mother and then transmitted to the child. Overwhelming evidence now indicates that a neurobiological basis for autism (Nicolson, 2004). However, these biological mechanisms are not fully understood.

Treatments for autism are also unclear. Diet therapy, medical therapy, and Applied Behavior Analysis (ABA) are some of the treatments physicians and parents have tried. A recent therapy that has been advocated on some websites for parents is a gluten free casein free (gfcf) diet. The purpose of this study was to collect preliminary information on factors that motivate parents to put their children on the gluten free/casein 
free diet. Factors that could provide barriers (lack of health care provider support, difficulty maintaining the diet, knowledge of how to implement the diet, etc) was also be explored. The information was collected through surveying parents that currently have their children on a gfcf diet. In addition, this project assessed nutrient deficiencies children might have while on the diet.

\section{Review of Literature}

\section{Background}

Autism is a word that sends confusion into the minds of the professionals and fear into the minds of parents. What is it? What causes it? How do we treat it? Like most disabilities, autism comes with many questions, most of which are still unanswered. Autism is a compound of two Greek words 'aut-' which means ‘self' and 'ism' which implies 'orientation or state'. Thus, autism could be defined as the condition of somebody who is unusually absorbed in him or her self. (Trevarthen 1996).

\section{Etiology of Autism}

There are many theories of how autism is caused. This has resulted in varied theories and research approaches. One theory suggests negative interactions between mother and child. The MMR vaccine has also been researched as a potential cause. In addition, a prenatal fault in brain development has also been suggested.

This fundamental brain disorder may be caused by a fault in genetic instructions for formation of specific systems in the brain, an infection or toxic chemical influence, or other factors. Whether autism affects other systems besides the brain is unknown. Some researchers suggest additional abnormalities in the gastrointestinal (GI) and immune systems. (Murch, 2005). 
What triggers the onset of symptoms is also unknown. While there is little doubt that some genetic components exist for autism, these are not necessarily the cause of the initial presentation. Current theories about triggers include: viral illness, overgrowth of Candida, the MMR vaccine, and the opioid excess theory (Garvey 2002). There is no evidence supporting viral and Candida triggers. Research by Wakefield and Montgomery, 1999 suggest that the MMR vaccine might be a trigger, but the consensus of expert opinion, both in the UK and worldwide, does not support this theory. In 1999 Fombonne stated, "In the light of the recent UK controversy about the possible association of autism with both inflammatory bowel disease and exposure to measles and mumps infections and the MMR immunization, it is worth noting there was no report in the epidemiological surveys of an association of autism with Crohn's disease, inflammatory bowel disorder or with wild measles or mumps infections. Moreover, surveys of autism conducted recently in the USA or in France after the introduction of the combined MMR immunization did not yield particularly high prevalence estimates”.

\section{Heritability}

The strongest evidence for heritability of autism comes from twin and family studies. Monozygotic (MZ) twins have been demonstrated to have a higher concordance than dizygotic twins (DZ). Concordance for autism has been documented between $60 \%$ and $90 \%$ in MZ twins, compared with 0 to $10 \%$ for DZ twins. Thus, Autism Spectrum Disorder (ASD) in general was shown to have high heritability (Spence 2004).

\section{Prevalence}

The prevalence rate for autism is a controversial topic. Autism has been described as occurring in approximately $15-27$ per 10,000 births depending on criteria. However, 
some estimate the rate at 2 per 10,000 (Wing, Gould 1979) for the full "Kanner " syndrome, for which the principal clinical features are: lack of responsiveness to other human beings, detachment from the parents or others, absence or abnormality of language development and speech, behavior abnormality with temper tantrums and repetitive activities, obsessive interest in small things, patterns, music, puzzles; insistence on preservation of sameness in environment. Other estimates of the prevalence of autism are 4.5 per 10,000 (Lotter, 1966) or 13.9 per 10,000 (Tanoue, 1988).

Researchers using the Diagnostic Checklist (Form E-2) found a rate of 1 per 20,000 (Rimland, 1971) for "Kanner" type autism and also found that the reliability of diagnosis by independent clinicians was extremely poor. At another extreme, in the context of discussing sub-classification of autism, some researchers refer to a rate of 27 individuals per 10,000 (Wing, Gould, 1979) who display what they term the "triad of social impairment" (social interaction, social communication, and imaginative behavior).

Thus, the central problem lies in the diagnostic criteria. There is a lack of clear consensus, and the criteria have changed over time. These problems, combined with the heterogeneity of the population and the poor diagnostic and subject selection criteria, render cross study comparisons difficult. In a carefully constructed study of the entire preschool population served by the National Health Service Trust in Staffordshire, England, Fombonne and Chakrabarti (2001) reported rates of 16.8 per 10,000 for autistic disorder. These contemporary studies offer rates that are greater than those previously reported (Fombonne and Chakrabarti 2001). Despite a variety of news reports in the media implying an epidemic of autism, it is likely that this does not represent a true increase in prevalence. Rather, fewer affected children are being misdiagnosed. This is a 
consequence of a diagnostic system that has improved methods of detection and now includes Asperger disorder and children with borderline symptoms (Batshaw 2002).

Researchers at the University of Cambridge (2005) systematically reviewed prevalence studies of autism spectrum disorder. They observed a high heterogeneity among the studies. The overall random-effects estimate of prevalence across studies for autism was 7.1 per 10,000 and for all of autism spectrum disorder the prevalence was 20.0 per 10,000. Moreover, they observed different diagnostic criteria and different ages for which the children were diagnosed (Williams, 2005).

A universal diagnostic system may help calculate the prevalence of autism. Mandell and Palmer (2005) studied the differences among states in the identification of autism spectrum disorder. They found that states ranged in the proportion of children diagnosed with ASD from 0.6 per 1000 to 4.6 per 1000 in 2000-2001. In adjusted analyses, education-related spending, the number of pediatricians in the state, and the number of school-based health centers in the state were positively associated with the administrative prevalence of ASD.

\section{Treatment-Behavior Therapy}

Professionals have tried many interventions to help treat autism. One of the most popular and effective techniques is applied behavior analysis or (ABA), an educational intervention technique (Olgetree, 2001) In ABA, skills are broken down into very small components and taught systematically, one skill building the foundation for the next. Since children with autism tend to require many more learning opportunities than their typically developing peers, a great deal of repetition is provided. In addition, data are collected to ensure that the strategy used to teach a particular skill is, in fact, working. 
Research has shown that some children who receive this type of intervention intensively (30-40 hours per week) early in their lives may reach a point where they can participate in regular education settings with typically developing peers. Some may even "lose" the diagnosis of autism (Olgetree, 2001) However, ABA intervention works differently for different children.

Early efforts to address the communicative impairments of persons with autism used traditional applications of ABA or discrete trial training (DTT). With DTT, trainers attempt to control all aspects of intervention and use imitation, prompting, shaping, and reinforcement procedures. Over time, prompts and cues are faded to promote independence. Recipients of DTT spend their time listening to, processing, and repeating stimuli. Initially, readiness skills are trained (e.g. eye contact, attending), followed by more sophisticated abilities, such as matching, imitation and spontaneous language. DTT has primarily been promoted by Dr. Lovaas and his colleagues (Ogletree 2001).

\section{Treatment- Nutritional Therapies}

Dietary interventions have also been used to help treat autism, but many of these lack empirical support. These interventions include vitamin therapy, and special diets such as the gluten free-casein free (gfcf) diet.

The vitamin that has undergone the most extensive study in the treatment of autism is vitamin B6. Several autism researchers have shown beneficial results with this vitamin, with effects that are potentiated and prolonged by co-administration of magnesium (Adams, Holloway, 2004), (Findling, 1997). An example of this combined approach is documented by Bernard Rimland (1988), who states that children who have been put on vitamin B6 and magnesium show improvement in eye contact and speech, 
reduction in self-stimulation behavior, more interest in the world around them, and fewer tantrums. In general, these patients are reported to appear considerably more "normal”. However his results are anecdotal, based only on parents' reports of how their children's behaviors changed before and after vitamin therapy. There have been several experimental studies with vitamin B6 that have shown statistically significant positive outcomes for children with autism; however, there have been no well designed studies to date (Whitely 2001).

Other vitamins that have been studied in connection with autism include vitamins A and C. In 1993, Dolske proposed that vitamin C's role in brain function could help treat or even prevent autism. In 2000, Megson proposed that the natural cis form of vitamin A may reconnect the hippocampal retinoid receptor pathway. This pathway is critical for vision, sensory perception, language processing and attention. However, research on these vitamins and factors has been minimal.

Another dietary supplement used by individuals to help reduce autistic behaviors is dimethylglycine (DMG). Kern et al (2001) reported no statistically significant behavioral improvements among 33 autistic children in a double-blind placebo-controlled study involving DMG. Some children appeared to respond positively to the DMG, and there was a smaller proportion of negative changes in the DMG group, but the quantitative changes in the DMG behavioral assessments were not significantly different from what was observed among children who received placebo.

Children with autism usually undergo many additional therapies to help them in their everyday lives. Some of these include: speech therapy, occupational therapy, physical therapy, listening therapy, floor time, early intervention and sensory therapy. In 
addition to these common therapies, some children are undergoing what are considered "controversial" therapies. One of these, chelation therapy, is the process of removing metal, primarily mercury, from the tissues of children with autism. Additional “controversial” therapies include: acupuncture, squeeze machine, aversives therapy, immune system enhancement. Researchers at the Regional Autism Center in Philadelphia found that more than $30 \%$ of autistic children were using some type of complementary and alternative medicine (CAM) with 9\% of those being potentially harmful. (Levy et al, 2003)

\section{Diet therapy}

Two diets are currently being used in autism. These are the specific carbohydrate diet, and the gluten-free, casein-free diet (gfcf diet.com). The specific carbohydrate diet was initially designed to treat inflammatory bowel disease and restore health to the digestive system. Parents of children with autism 'discovered' this diet and have since used it in their homes (The Specific Carbohydrate Diet website, kids and the specific carbohydrate diet. www.pecanbread.com, accessed August 2, 2005). Carbohydrates that are permitted on this diet have a molecular structure small enough to allow them to be transported across the surface of the small intestine into the blood stream. The diet starts with limited kinds of carbohydrates, and gradually adds more as the gastro-intestinal tract heals.

The most popular nutritional treatment or "fad" diet currently used for autism is the gfcf diet (www.gfcfdiet.com). Proponents claim this diet will improve eye contact, speech, social contact, motor coordination language and sleep patterns, decrease ritualistic behaviors and even decrease seizures (The gluten free casein free diet website 
www.gfcfdiet.com, accessed May $5^{\text {th }} 2005$, Kidd, 2003). The diet is popular because it promises great results, is non-invasive, and parents feel there is nothing to lose and potentially a lot to gain by adopting it. (The Autism Network for Dietary Intervention (www.autismndi.com), accessed May $5^{\text {th }}$ 2005.)

The gluten free casein free diet is based on the "opioid excess theory,” first proposed in 1979 by Panksepp. This theory suggests that opioids present in food trigger neurological changes. In normal digestion, proteins are digested in stages by enzymes, being first converted to peptides (the intermediate compounds), and then to smaller amino acids components. The amino acids are then absorbed into blood capillaries in the mucosal membrane of the gut and carried via the blood to the liver. Panksepp suggested that the larger peptides are generally unable to cross this mucosal membrane barrier, but when they do, they can act as opioids, affecting neurotransmitters in the brain and central nervous system, causing abnormal behaviors and/or activity. These larger peptides are derived from the incomplete breakdown of protein from certain foods, particularly gluten (from wheat and other cereals) and casein (from dairy foods). In individuals who do not have autism, leakage of these peptides is minimal and causes little or no effect (Garvey 2002). However, in individuals with autism, a higher percentage of opioid peptides reach the central nervous system. Advocates of the gfcf diet for children with autism, state, “... to most autistic children, gluten and casein are the equivalent of poison. They leak into the gut undigested and attach to the opiate receptors of the brain. Essentially, many children with autism are "drugged" on wheat and milk products, as if they were on a morphine drip” (Defeat Autism Now DAN website www.autism.org/dan. accessed May 5th 2005.) 
What would cause the excess leakage of peptides in some individuals with ASD? How do the peptides enter the CNS and have such detrimental effects? Shattock (2002) and colleagues at the National Autistic Society (NAS) have come up with three possible explanations for this theory: 1) Formation of excess peptides in the gut, 2) An abnormally permeable mucous membrane in the gut, 3) The blood brain barrier is more permeable (Garvey 2002).

While none of the above theories has any evidence to support it, one group of researchers (Pavonne et al, 1997) did investigate whether improvement in children’s behaviors after being on the gfcf diet could be linked to undiagnosed celiac disease. Celiac disease, which affects $0.1-0.2 \%$ of the population, is a genetic disorder that affects the small intestine. It renders individuals immunologically sensitive to gliadin, a constituent of gluten, found in wheat, rye, oats, and barley. When gliadin is eaten, the body mounts an auto-immunological attack damaging the villi of the small intestine and reducing their ability to absorb nutrients. Repeated exposure to gliadin causes atrophy of the villi, resulting in malabsorption. Since an association between celiac disease and certain neurological complications had been demonstrated, Pavonne et al wondered if some of the behaviors and symptoms of autism might be associated with celiac disease. They screened 120 children with celiac disease for autism, and screened 20 children with autism for celiac disease. They found no correlations between autism and celiac disease.

Two single-blind, controlled studies by Knivsberg et al (2002, 2003) attempted to evaluate the effect of the gluten free, casein free diet on children with autism after one year on the diet. While the children were randomly assigned to either the diet or the 
control group, assessment of their cognitive, linguistic, and motor skills prior to and after following the diet were based only on subjective reports by the parents.

While the diet calls for the elimination of both casein and gluten, supporting research cited by proponents does not necessarily suggest that both proteins need to be eliminated in order to achieve positive result. Lucarelli et al (1995) reported marked improvement in the behavioral symptoms of autistic patients after an eight week period of a diet with no casein but gluten was not eliminated. Additionally, Lucarelli et al reported that compared to controls, autistic patients had significantly higher levels of IgA specific antibodies for casein, lactoalbumin, Beta-lactoglobulin and ovalbumin after the eight week trail.

Many ASD patients also suffer from recurrent/chronic ear infections, sinusitis, viral infections, and chronic diarrhea/constipation. Despite parental beliefs that these symptoms are further proof of abnormal intestinal function and food allergies, these claims have not been substantiated by conventional immune workups (Gupta et al, 1996). Although many parents, teachers, and therapists have reported improvements in children following the gfcf diet, these reports are anecdotal. There have been no double blind, case controlled studies completed to date.

How do parents hear about the gluten free casein free diet? The Internet is probably the most popular source of information. When the word "autism" is put into the "Google" search engine, 7 out of 18 websites on the first page give information to parents about the gfcf diet. Parents who "Google” directly for the gfcf diet will turn up pages of websites devoted exclusively to the diet. Further, the (www.gfcfdiet.com) website currently has over 5000 families as members; thus making it appear that many parents 
endorse the diet. This is reinforced by The Autism Network for Dietary Intervention

(www.autismndi.com), which offers entities such as support groups for parents to communicate with each other on implementing dietary treatment. Parents can depend on many Internet sites for information. The major autism support groups include: National Autism Society (NAS), Defeat Autism Now (DAN), The Autism Network for Dietary Intervention (ANDI) and the Gluten Free Casein Free Diet. All of these organizations help parents by providing information and support. In addition to the Internet, there are a number of books that recommend the diet for children with autism, five being readily available on www.amazon.com. Moreover, the diet has pop media exposure from being showcased on television shows such as Oprah, one of the most widely watched television programs in the country (June 2, 2000).

Although there is no credible supporting research for the diet, parents can find a number of articles that appear to present credible, researched information. A good example is the September/October 2003 issue of Alternative Therapies. This review article cites over 80 references that support the hypothesis that casein and gluten contribute to ASD. However, over half the references are from non-peer reviewed articles, and the remaining references provide only background information. No credible clinical studies are cited in this article (Kidd, 2003).

While the gfcf diet is non invasive, it is not necessarily harmless. The diet may have adverse nutritional consequences. Cornish (2002) analyzed 29 diet records of children with autism following the gfcf diet. Of children not following the gfcf diet, 32\% had lower than optimal intakes of zinc, calcium, iron, vitamin A, vitamin B12, and riboflavin in the non-diet group. Of the children following the gfcf diet, 50\% had 
insufficient intakes of zinc and calcium. Bowers (2002) analyzed diet records of 26 children with autism who were following the gfcf diet and found that while they did meet or exceed dietary reference values for energy and protein, they had inadequate intakes of other nutrients.

Nutritional inadequacies are likely to become worse over time. This is especially important in light of the fact that proponents of the gfcf diet recommend that children stay on the diet anywhere from 3 months to 18 months, or indefinitely (Reichelt, 1990, (Princeton University www.princeton.edu accessed May $10^{\text {th }} 2005$, The Patient Center www.patientcenter.com accessed May $10^{\text {th }}$ 2005, The Autism Coach, Autism Spectrum Products, www.autismcoach.com DAN! accessed May $\left.10^{\text {th }} 2005\right)$. Thus, children on the gfcf diet may be more likely to develop significant nutrient deficiencies the longer they stay on the diet.

Factors that may make the diet challenging for parents include children's food selectivity, and the time, energy, planning, money, and access to alternative foods that are required. Many children with autism have a tendency to be food selective; therefore, putting these children on the gfcf diet may increase behavioral problems and cause the diet to be unsuccessful in the long run. To follow either a gluten free or casein free diet, parents must be willing to buy special food products and find the time to prepare special recipes and menus. Parents must also learn to read food labels and recognize which food additives are gluten based or casein based. Eliminating both gluten and casein foods leaves significantly fewer foods that can be eaten. In addition, gluten and dairy substitutes are more expensive and less widely available. 
While it is possible to meet nutrient needs on a gluten-free, casein-free diet if parents are knowledgeable enough about nutrition, the number of parents who are knowledgeable is unknown (Whitney, 1999). Both Cornish and Bowers state that parents planning to put their children on the gfcf diet should consult dietitians to insure adequate intake. How many parents do consult dietitians is unknown. Whether the providers they do consult are properly credentialed is unknown. The number of families with food selective children who try the gfcf diet is also unknown.

\section{Statement of the Problem}

Although there is not enough scientific evidence to support the inclusion of the gfcf diet in the treatment of autism, this diet has nevertheless become very popular with parents of children with autism. Dietary management of children with autism is complex, as excluding gluten and casein greatly restricts childrens' diets and may contribute to vitamin and mineral deficiencies. Children on the gfcf diet should have the input of a registered dietitian (RD) to insure diet adequacy. A gluten-free, casein-free diet for the treatment of autism has the following potential problems:

1. Gluten and casein are in foods and beverages that serve as major sources of energy for a growing child, and children on this diet would not receive them.

2. A child may not reach the Dietary Reference Intake DRIs for individual nutrients; specifically vitamin A, vitamin D, fiber, and calcium.

3. Corrective measures may not be done to keep specific nutrients in the diet.

4. It would be hard to maintain such a restrictive diet.

5. Proper professionals might not be consulted. 
6. Overlapping therapies could result in false beliefs about the diet's efficacy.

Since many parents are still attempting the gfcf diet, the purpose of this study was to collect preliminary information on factors that motivate parents to put their children on the diet. The specific aims were:

1. To determine how parents heard about the gfcf diet.

2. Reasons why parents choose the gfcf diet.

3. How parents perceived the effectiveness of the diet,

4. Difficulties parents have in implementing and maintaining the diet.

5. Did parents consult professionals; if so, which ones.

6. Other therapies the children were receiving while on the diet.

\section{$\underline{\text { Methods }}$}

This author became interested in the gluten free casein free diet while attending the Feeding and Swallowing Clinic at West Virginia University's Center for Excellence in Disabilities. Hearing parents praise the diet and its effects on their children raised concerns. From a nutritional standpoint, an elimination diet can be deficient in many nutrients if not administered correctly. Many questions arose that only parents could answer.

The Institutional Review Board (IRB) of West Virginia University approved this research project for exemption. A survey (Appendix 1) was developed to identify specific aims of the project. The survey included questions about the challenges that parents face while their children are on the diet, if they consult health care professionals for support of the diet, and whether they believe they are seeing changes in their children due to dietary 
intervention. A letter to parents (Appendix 2) was developed to explain why the study was being done. Participants for the project were recruited at four different conferences focusing on autism. The project was explained to conference participants and individuals were invited to voluntarily sign up. In addition, participants were recruited through the AutismNDI (autism network for dietary intervention). All participants for this project were parents of children with autism. An electronic version of the survey was sent to parents that had e-mail addresses available on the website to participate in supports groups. One hundred and sixty-two surveys were sent electronically and eighty-five were mailed. Survey results were entered into a data base. A few surveys were returned with diet histories. Diet analyses were performed using Food Works Nutrient Analysis Software: The Professional's Choice (New Jersey 2004). This program uses the Dietary Reference Intakes (DRIs) to analyze results. The DRIs replaced and expanded the Recommended Dietary Allowances (RDAs) in 1998. The DRIs provides a set of standards for optimal intakes of nutrients. Results of the analyses were returned to those parents who requested to see them. Total energy (calories in the form of fat, protein and carbohydrates), vitamin D, vitamin A, fiber and calcium were the nutrients examined. These nutrients were selected because they are predominantly found in foods containing gluten and casein. 


\section{Results}
A. Survey Results
Data collected in this project came directly from parents of children with autism.

Eighty six percent of the returned surveys were completed by mothers. Twelve percent of the surveys were completed by fathers, and $2 \%$ were completed by both parents. Fiftythree out of 247 surveys (21\%) were returned. The sample size " $n$ ” for each table is different due to multiple answers given by parents, or due to survey questions not answered.

Table 1: How did parent hear about the gluten- free, casein- free diet. When parents were asked how they first heard about the gfcf diet (Table 1), 32\% cited "Parent Magazine” and Karyn Seroussi’s article Unraveling the Mystery of Autism and Pervasive Developmental Disorder: A Mother's Story of Research and Recovery. An additional $28 \%$ of parents learned of the gfcf diet from the Internet, and the remaining $40 \%$ learned about it from friends, doctors and research.

Table 1 Parents' initial source of information about the gfcf diet. (n=59)

\begin{tabular}{|c|c|}
\hline Internet & $17(28 \%)$ \\
\hline Media (Parent Magazine) & $19(32 \%)$ \\
\hline Other responses & $23(40 \%)$ \\
\hline Health care professional & $7(11.9 \%)$ \\
\hline Books/Research & $7(11.9 \%)$ \\
\hline Friend/Relative & $9(15.2 \%)$ \\
\hline Unanswered/No response & 0 \\
\hline
\end{tabular}


Table 2: Why did parents start the diet? Twenty-five percent of parents cited desperation and $19.2 \%$ reported "just deciding to try it" as the main motivating factors for trying the diet (Table 2). Additional reasons for starting the diet, included: “medical problems” consisting of vomiting, diarrhea, stomach pains. Blood test results were also mentioned frequently (29\%). Seventeen percent cited advice from other people as the main motivating factor. Finally, almost $10 \%$ of parents felt it was necessary to implement the diet because they understood it to be a treatment for autism

Table 2 Motivating factors to try the gfcf diet $(n=52)$

\begin{tabular}{|l|l|}
\hline Desperation & $13(25 \%)$ \\
\hline “Just decided to try it” & $10(19.2 \%)$ \\
\hline Influence of others & $9(17.3 \%)$ \\
\hline Medical reasons (vomiting, diarrhea, & $15(29 \%)$ \\
allergies) & \\
\hline “It's a treatment for autism” & $5(9.6 \%)$ \\
\hline Unanswered/ No response & 0 \\
\hline
\end{tabular}

Table 3: How long did parents keep their children on the diet? The time range for children being on the diet was 2 weeks to 7 years, with $47 \%$ of children reported to have been on the diet for 3 or more years (Table 3). Twenty-four percent of the children were on the diet for 1 to 3 years, while $18 \%$ of parents reported they were just starting the diet or had been on it for less than a year. In addition, $12 \%$ of parents stated they would not put their child on this diet. 
Table 3 Length of time children were/are on the gfcf diet $(n=51)$

\begin{tabular}{|l|l|}
\hline $1 \frac{1 / 2}{}$ months-11 months & $9(18 \%)$ \\
\hline $1-3$ years & $12(24 \%)$ \\
\hline 3 years or greater & $24(47 \%)$ \\
\hline Unanswered/ No response & 6 (parents who wouldn't try the diet) $(12 \%)$ \\
\hline
\end{tabular}

Table 4: What foods were eliminated while on the diet? When asked what foods were eliminated, $82 \%$ claimed to have removed gluten and all dairy (Table 4). Seventeen percent of parents reported removing milk only and claimed that this made the diet casein free. Many parents (92\%) reported removing more than just gluten and casein from their children's diet. Other foods that were removed included; nuts, eggs, soy, corn, beef, dyes, artificial colorings and additives, yeast, vinegar, processed sugars, juice and citrus foods.

Table 4 What foods were eliminated $(n=51)$

\begin{tabular}{|l|l|}
\hline Gluten/Casein & $42(82 \%)$ \\
\hline Milk & $9(17 \%)$ \\
\hline Subtotal & 51 \\
\hline Eliminated more than gluten/casein & $47(92 \%)$ \\
\hline
\end{tabular}

Table 5: Did children like the foods that were not allowed on the diet? Thirtytwo percent of parents stated that their children liked all of the foods that had been removed (milk and cheese being the two most popular foods mentioned). (Table 5) 
Table 5 Of the foods eliminated which ones did your child like $(n=59)$

\begin{tabular}{|l|l|}
\hline Milk & $12(20 \%)$ \\
\hline Cheese & $5(8 \%)$ \\
\hline Bread/Pasta & $9(15 \%)$ \\
\hline All of them & $20(34 \%)$ \\
\hline Snack food & $13(22 \%)$ \\
\hline
\end{tabular}

Table 6: Did parents find the diet hard to maintain, and if so what were the most difficult aspects of the diet? Thirty-nine percent of parents stated that the diet had been hard to maintain at first but not at present, while 16\% reported that following the diet was very hard and was their full time job (Table 6). Twenty-eight percent of parents did not feel the diet was hard to implement or maintain in their home. When asked about the most difficult part of maintaining the diet, 34\% of parents stated: eating out, and traveling, while $10 \%$ reported expense as the most difficult aspect of the diet. The remaining $54 \%$ of parents cited a number of other difficulties that included: school lunches, birthday parties, providing a variety of foods, planning and feeding other family members. Prior to starting the diet, $45 \%$ of children were reported to have had behavioral feeding problems (food selectivity) 
Table 6 Difficulties maintaining the gfcf diet $(n=51,100)$ respectively

\begin{tabular}{|l|l|l|l|}
\hline $\begin{array}{l}\text { Is the diet hard to } \\
\text { maintain (n=51) }\end{array}$ & $\begin{array}{l}\text { Most difficult part } \\
\text { of maintaining the } \\
\text { diet (n=100) }\end{array}$ & \\
\hline Yes & $4(7 \%)$ & Eating out/ Travel & $34(34 \%)$ \\
\hline No & $16(28 \%)$ & Expense & $10(10 \%)$ \\
\hline At first & $22(39 \%)$ & Remaining answers & $54(54 \%)$ \\
\hline Very Hard & $9(16 \%)$ & $\begin{array}{c}\text { Social } \\
\text { gatherings/school }\end{array}$ & $24(24 \%)$ \\
\hline & & Planning/variety & $17(17 \%)$ \\
\hline Unanswered/No & $6(11 \%)$ & $\begin{array}{c}\text { Unanswered/ } \\
\text { Nosponse response }\end{array}$ & $7(7 \%)$ \\
\hline
\end{tabular}

Table 7: Did parents see behavioral changes when they put their child on the diet? Did parents feel that these changes were due to the diet? Were the children on any additional therapies? Sixty-four percent of parents stated that they had seen positive changes in their children since starting the diet (Table 7). Improvements included: increased eye contact, increased speech, less crying, fewer tantrums, fewer ear infections, and less diarrhea. Twelve and a half percent of parents reported no behavioral changes since starting the diet. While 57\% of parents reported that their children's behavior changes were due to the diet, $61 \%$ reported that their children were receiving additional therapies while on the diet. Only $15 \%$ of parents reported that diet therapy was the only therapy their children were receiving. 
Table 7 Behavioral changes reported by parents/ Number of parents who believed improvement was solely due to the gfcf diet. $(n=56,56,51)$ respectively

\begin{tabular}{|l|l|l|l|l|l|}
\hline $\begin{array}{l}\text { Behavioral } \\
\text { changes }\end{array}$ & & $\begin{array}{l}\text { Changes } \\
\text { due to diet }\end{array}$ & & $\begin{array}{l}\text { Was the } \\
\text { child on any } \\
\text { other } \\
\text { therapy }\end{array}$ & \\
\hline Yes & $36(64 \%)$ & Yes & $32(57 \%)$ & Yes & $31(61 \%)$ \\
\hline No & $7(12.5 \%)$ & No & $\begin{array}{l}7(\text { n/a to } \\
\text { correlate } \\
\text { with no } \\
\text { changes } \\
(12.5 \%)\end{array}$ & No & $8(15 \%)$ \\
\hline Maybe & $1(2 \%)$ & Maybe & $5(9 \%)$ & & \\
\hline No response & $12(21.5 \%)$ & No response & $12(21.5 \%)$ & Unanswered & $12(24 \%)$ \\
\hline
\end{tabular}

Table 8: What other therapies were the children on? Twenty-one percent of children were receiving speech therapy in addition to diet therapy (Table 8). Applied behavior analysis (ABA) (14\%), and occupational therapy (15\%) were second to speech therapy. Other therapies mentioned included: floor time program, listening therapies, vitamin therapy, chelation, developmental therapy, music therapy, sensory OT therapy, physical therapy, discrete trial training (DTT), medication for anger, auditory therapy, and birth to three early intervention programs. 
Table 8 Other therapies children received in addition to the gfcf diet. $(n=110)$

\begin{tabular}{|l|l|}
\hline Yes (no specific therapy noted) & $4(4 \%)$ \\
\hline Applied Behavior Analysis (ABA) & $15(14 \%)$ \\
\hline Occupational Therapy (OT) & $16(15 \%)$ \\
\hline Speech Therapy & $23(21 \%)$ \\
\hline Physical Therapy (PT) & $5(5 \%)$ \\
\hline \begin{tabular}{l} 
Vitamin/Chelation Therapy \\
\hline $\begin{array}{l}\text { Floor time/listening/developmental/Early } \\
\text { Intervention/Sensory OT/Other }\end{array}$
\end{tabular} & $16(14 \%)$ \\
\hline None/no answer & $20(17 \%)$ \\
\hline
\end{tabular}

Table 9: Did parents consult a health care professional? Twenty-nine percent of parents said they had not consulted a physician or dietitian for support of the diet, while the remaining $71 \%$ reported getting help from a physician or dietitian over the Internet. (Table 9)

Table 9 Consultations with Health Care Professionals concerning the gfcf $\operatorname{diet}(n=51)$

\begin{tabular}{|l|c|}
\hline No/unanswered & $15(29 \%)$ \\
\hline Remaining answers & $37(71 \%)$ \\
\hline $\begin{array}{l}\text { Did you consult a health care } \\
\text { professional about the diet? } \\
\text { (profession not specified) }\end{array}$ & $16(31 \%)$ \\
\hline Physician & $14(27 \%)$ \\
\hline Dietitian & $7(13 \%)$ \\
\hline
\end{tabular}




\section{Table 10: Did parents feel their children were receiving a balanced diet, and}

were they using supplements? Seventy-five percent of parents said their children were not lacking any nutrients and were receiving a balanced diet while on the gfcf diet. (Table 10) However, $10 \%$ still felt that their children might be lacking calcium, folic acid, B12 and other important nutrients. A total of $67 \%$ of parents reported giving their child some type of supplement.

Table 10 Parent's belief about their children receiving a balanced diet while on the gfcf diet. $(\mathrm{n}=51)$

\begin{tabular}{|l|l|l|l|}
\hline Balanced Diet & & Use Supplements & \\
\hline Yes & $38(75 \%)$ & Yes & $34(67 \%)$ \\
\hline No & $5(10 \%)$ & No & $6(12 \%)$ \\
\hline $\begin{array}{l}\text { Unanswered/No } \\
\text { response }\end{array}$ & $8(16 \%)$ & & $11(22 \%)$ \\
\hline
\end{tabular}

Table 11: What supplements were the children receiving? Nine percent stated that they used supplements but didn’t name individual ones. (Table 11) Some of the supplements mentioned included: a multivitamin (24\%), calcium (17\%), and cod liver oil (9\%). The remaining 40\% included: Vitamins B12, B6 and C, enzymes, zinc, iron, flax, amino acids, omega 3,Trimethylglycine (TMG), Acidophlus, Biocidin, Smart Oil, minerals, folic acid, Docosahexaenoic acid (DHA), Dimethylglycine (DMG), and Tryptophan. 
Table 11 Supplements used by parents $(n=82)$

\begin{tabular}{|l|l|}
\hline Yes, but not specified & $8(9 \%)$ \\
\hline Multi vitamin & $20(24 \%)$ \\
\hline Calcium & $14(17 \%)$ \\
\hline Cod liver oil & $8(9 \%)$ \\
\hline $\begin{array}{l}\text { Others (Vitamin B12, B6, C, enzymes, } \\
\text { zinc, iron, AA, omega 3, TMG, Smart oil, } \\
\text { minerals, folic acid, DHA, DMG, } \\
\text { acidophuls, biocidin, tryptophan }\end{array}$ & $32(40 \%)$ \\
\hline
\end{tabular}

\section{B. Diet Record Results}

In addition to surveys, ten diet records were collected and six were analyzed. Four diet records were excluded from analysis because two of the children were no longer on the diet, and two records had only been completed for one day. Of the six analyzed, all appeared, at first, to be completely gluten and casein free. One did actually contain gluten, however it seemed to be a error in reporting. Total energy (calories in the form of fat, protein and carbohydrates), vitamin D, vitamin A, fiber and calcium were the nutrients examined upon completion of analysis. One-hundred percent met the requirement for energy (calories) in accordance with age, height, weight and sex of the individual. Four diet records met the DRI for vitamin A, while none met the requirements for vitamin D. However if exposed to the proper amount of sunlight per day, the body can make its own vitamin D. Two diet records met the DRI for fiber, while none met the 
requirements for calcium. All of the parents who returned diet records stated that they give their children supplements or multi-vitamins of some kind.

Table 12 Diet Record Analysis (percent of DRI)

\begin{tabular}{|l|l|l|l|l|l|}
\hline $\begin{array}{l}\text { Child } \\
\text { Number }\end{array}$ & $\begin{array}{l}\text { Total } \\
\text { Calories } \\
(\mathbf{\%})\end{array}$ & Fiber (\%) & $\begin{array}{l}\text { Calcium } \\
\mathbf{( \% )}\end{array}$ & $\begin{array}{l}\text { Vitamin A } \\
\mathbf{( \% )}\end{array}$ & $\begin{array}{l}\text { Vitamin D } \\
(\mathbf{\%})\end{array}$ \\
\hline 1 & 117 & 54 & 35 & 186 & 4 \\
\hline 2 & 204 & 60 & 62 & 75 & 5 \\
\hline 3 & 151 & 107 & 77 & 209 & 0 \\
\hline 4 & 146 & 37 & 21 & 322 & 0 \\
\hline 5 & 127 & 126 & 36 & 593 & 6 \\
\hline 6 & 360 & 23 & 28 & 68 & 0 \\
\hline
\end{tabular}

\section{$\underline{\text { Discussion }}$}

Factors that could have biased the results include small sample size, self selected data, self reported data, and parental perspective. The sample size $(n=53)$ represents a return percentage of only $21 \%$ of the original 250 surveys sent out. Participants were recruited through autism related conferences and the gfcf diet website. Since this website was designed to help parents implement the diet in their homes, parents on the list serve were likely to be in favor of the diet. Self-reporting of data is a weakness in any research study. Parents may be reluctant to report negative things about their children. Last, Shek 
(1998) found that mothers may have a tendency to be more lenient than fathers when answering questions concerning their children Since $86 \%$ of returned surveys were filled out by mothers, parental perspective could also have biased the results.

Despite the likelihood that survey respondants would all be in favor of the diet, $11 \%$ of parents who responded stated "I would not do that to my child", "I won't try that diet”, “I don’t believe autism has a dietary component”, and “I’m so disgusted with the gluten free casein free movement as it allows many other problem foods and by products along with harmful food additives”.

One parent reported that she started the diet due to advice from a health care professional (a dietitian); however, 28\% of parents first found out about treatments for their children over the Internet. In addition, 15\% relied on friends, and 12\% relied on their own research (possibly Internet), which suggests that as many as 55\% of parents could have received information concerning treatment for their child with autism that was false. One parent stated "after researching the diet and determining that my son had several factors for food intolerance, we started the gfcf diet”, this 'diagnosis' of food intolerance was made without a doctor and correlating with information found on the Internet. Other statements given by parents based on information found on the Internet and not confirmed by medical testing included: "my son was injured by vaccines and had to go on the diet", "we suspected that her craving for cheese perhaps meant that her body was addicted to the opiate-like highs created by her inability to digest the gluten and casein proteins", "my child had psychotic thoughts", "my child is a responder”, and "she was having abnormal digestive problems that none of the gastro doctors could help”. However, none of these observations were confirmed by a licensed physician. In another 
case one father explained "My son was vomiting and had diarrhea for three straight months. The diet was the only thing that helped.” A physician’s supervision would be necessary in such a case with dehydration being the main concern, but when asked if they consult a health care professional, these parents said they had not.

While $71 \%$ of parents said that they had consulted health care professionals concerning the gfcf diet, one parent stated "We follow the DAN! (Defeat Autism Now) protocol strictly, under the care of three different DAN practitioners". This "supervision" is done mainly over the Internet. She also stated, "our regular pediatrician is supportive, but she doesn't believe in the diet. She does however acknowledge that my son has made amazing progress". In addition, this mother claimed that "absolutely, hands down, no question” the diet is the reason for her son's behavioral changes; nevertheless, she admits that her son is no longer on the diet. In cases where licensed physicians were consulted, parents did not necessarily follow their physicians' or dietitians’ advise, one parent stated, "the physician helps but does not agree with what I'm doing”. Another frustrated mother, when asked if she did anything to supplement her son's diet stated, "No, I do not know how to get them (supplements). No doctors want to acknowledge this gfcf diet”. In addition she reported that, "no doctor will help her and the dietitian would only ask what I was feeding my child so she could do an analysis”. This might be the reason that one parent reported that when she looks for medical and nutritional information, it is "mostly through the Internet and books.” In some cases, parents have been the ones to bring the information about the gfcf diet to their health care providers. One mother claimed, "When I started the diet, doctors were not allowed to help me any more than as consultants. I was their educator.” 
Another parent found herself in a role reversal with her health care providers who wanted to provide unproven vitamin supplementation: “They (the providers) wanted to have him conform to other kids in the autistic spectrum. He is not other kids. He is doing great and you wouldn't think there is anything wrong with him if you met him. When the doctor wanted to give vitamin B-6 shots on a weekly basis, I said, "only if he is deficient.” He tried to convince me that that is the protocol and gave me a speech, but I insisted he be tested for a deficiency. The blood test showed his B-6 levels were fine. I said no.”

The recommended daily allowance range for vitamin B6 is 1.2-1.7mg with a toxicity level occurring when doses reach $2 \mathrm{~g}$ or greater per day for two months or longer. The average dosage for vitamin B6 supplementation shown in different research studies range from 100-600 mg per day. In addition most foods included on the gfcf diet are good sources of vitamin B6 (green leafy vegetables, meat, fish, poultry, legumes, and fruits). If these foods are included in a daily diet of a child with autism, it would not be necessary to supplement with vitamin B6.

Even with the small sample size of this study, the small number of parents (4\%) who reported using vitamin B6 or magnesium illustrates how fad theories of treatment of autism come and go. Of those 4\% who reported using vitamin B6 and magnesium, none reported combining the two.

Motivating factors contributing to parents' decision to start the diet included the desire to help their children be "more normal”, "less spacey”, and "like other kids". Forty-four percent of parents started the diet due to desperation or, "just decided to try it”. However, $10 \%$ of parents did state they started the diet because it was a proven 
treatment for autism. One parent reported the reason for starting the diet was "I recognized that my child 'fits the profile’ of a responder. He gorged milk, tantrumed constantly, had terrible diarrhea, etc.” Another stated, "My son identified with many of the food allergy traits on the ANDI website, so we started the diet.” Two separate parents said their main motivation for starting the diet was that it was "non-invasive" and didn't require medication.

A majority of parents did believe the diet was effective, with $67 \%$ reporting that they had seen behavioral changes in their children with the administration of the gfcf diet, and 57\% reporting that they believed the changes were due to the diet. Ten percent of parents stated they had not seen any changes since they started the diet, of which $4 \%$ were not sure. Of parents who claimed that their children had made improvements on the diet and that the improvements were strictly due to the diet, $17 \%$ of them no longer had their children on the diet. Reasons given for discontinuing the diet included: difficulty, stress of following the diet, expense, and difficult behavior reactions from the children.

However, $80 \%$ of parents surveyed were still following the diet and felt it was worth the challenge. One parent stated "it is very, very tough, but it can be done. We are three years proof of that fact”. Despite some of the inconveniences of the diet many parents said the effort was worth it. Having a severely autistic child is much harder,” reported one father. A mother stated "At first it is overwhelming, but we were determined and in a three month period our son started talking and was part of our lives. Before he was in his own little world and would not respond to anyone or anything. The fog was lifted!” 
Sixty percent of children on the gfcf diet were reported to be receiving other therapies in addition to the diet. Without independent measurement of behavioral changes plus elimination of all other therapies, it is impossible to determine what effect (if any) the gfcf diet has had on these children. Yet the majority of parents (57\%) firmly believed the diet was working. "Absolutely, hands down, no questions, YES these changes are due to the diet", one mother claimed. Another mother stated "Yes, no other changes in his services occurred in this time frame, it had to be the diet."

When parents were asked what foods they eliminated from their children's diet, 75\% reported to remove all foods containing gluten and/or casein. The remaining 13 parents reported removing milk only and wheat only. Of these 13 parents, 11 claimed to see behavioral changes and said the changes were due to the diet, even though they were not following it correctly. While 6 children were receiving other therapies, 7 children were not. Improvement in behavior could have been due to other therapies, different interactions with children due to different expectations or simply wishful thinking.

Of the six diet records analyzed, only one proved to be gluten containing, although it seemed to be a mistake in reporting. This may show that the parents who took the initiative to fill out and return the diet record had also taken the initiative to learn gluten free-casein free requirements. It is important to note that the sample was a biased sample, so many of these parents were already very knowledgeable in this area.

Although this was a very small sample, diet record results were similar to those of Cornish (2002) and Bowers (2002). In all three, energy requirements were met. Cornish listed nutrient deficiencies for calcium, iron, zinc, copper, thiamin, riboflavin, niacin, vitamin C, vitamin A, vitamin B6, vitamin B12 and folate, while similar nutrient 
deficiencies were seen in this study with vitamin A and calcium. However, vitamin A and calcium were the only two similar nutrients analyzed. Therefore there may be additional similarities if other nutrients were explored.

Eliminating whole food groups such as dairy and many carbohydrates for an extended time period without supplementation could be detrimental to health. Fortyseven percent of parents surveyed had had their children on the gfcf diet for three years or more. However, since $81 \%$ of parents surveyed also gave their children a supplement of some kind, most parents were taking additional measures to make sure that their children’s nutrient needs were being met. However, some (19\%) children might still be at nutritional risk due to an elimination diet of greater than three years with no supplements added. In addition, some of the supplements used were not vitamin supplements. Since no diet records were submitted for children not taking supplements, evaluations of their nutritional status could not be made.

The majority of parents said they felt that the diet was working for their children. The implication is that they will continue to use it because they are seeing results and feel that their children are not in any danger of nutrient deficiencies. Many parents also reported that the difficulties of following the diet were a small price to pay for the improvements their children are making.

\section{Conclusion}

Parents responding to this survey were self selected and represented a small sample of the population of parents following the gfcf diet, a fad treatment for autism. Despite the challenges of following the diet, the majority of parents in this sample were willing to make the effort because they believe the diet is making a positive difference in 
their children's behavior. Thus, it may be concluded that they felt the perceived benefits outweighed the risks and challenges.

Although most parents in the sample believed that the gfcf diet was helping their children's behaviors and performance, the likelihood that this was true is extremely low. First, there were no consistencies in how the diet was followed. Some parents eliminated a few foods, while others eliminated many. Some respondents did not eliminate gluten and casein but still thought they were still following the gfcf diet. Parents also reported giving many different nutritional supplements to children. Second, many children were reported to be receiving additional therapies. Third, no independent objective criteria were used to measure changes in children's behaviors.

Although a very small sample of diet records was analyzed, the results suggest that children on the gfcf diet may not meet the DRIs for calcium and vitamin D, and perhaps other nutrients, as reported by other researchers (Cornish, 2002, Bowers, 2002). Parents determined to put their children on the gfcf diet should get detailed nutritional information from a dietitian to insure diet adequacy. Many parents in this survey did consult a health care provider, but it is not clear how many parents were correctly following the advice they had been given, nor how many children in this sample were meeting the DRIs. In addition, a number of parents did not consult credible health care providers although they may have believed they had.

Last, with the information on fad treatments for autism so widely available in the media and on the Internet, discouraging parents from following unproven and potentially dangerous treatments remains a very challenging task. 
There is no known cure for autism. While DDT and ABA are legitimate treatments that can help improve functioning, they demand a lot of time and patience before positive results are seen. Parents may be dissatisfied with these treatment approaches or simply want more options. For many, the Internet provides an easily accessible source of hopeful information on the treatment of autism. However, there is no regulation of information posted, and many sites provide unfounded and potentially dangerous information. Thus, health care providers should be sensitive to what parents think is "fact" and their willingness to try substantiated "advice".

\section{Applications}

\section{For Physicians, Dietitians and Other Providers:}

Remember that living with a child who has autism can be extremely stressful. Parents may be turning to fad diets because they are willing to try anything that may help their children. Many parents don’t seek professional medical advice before trying the gfcf diet. For those that do make the effort to come to you, it is important to establish a relationship where they will be willing to hear your suggestions and come back for follow up visits. Maintain an open and non judgmental attitude. Give parents information on how to implement the gfcf diet without causing nutritional deficiencies. Discuss with parents what constitutes a reasonable amount of time to be on the diet. Three months is the usual suggestion. More important than anything- take the time to assist parents in determining how they will measure signs of improvement or change in their children. Parents can then discover on their own whether the diet is working and worth continuing. For parents who do continue to keep their children on the diet beyond three months, 
stress the importance of follow up visits to the dietitian to insure that growth and nutrient needs are being met.

\section{For Parents:}

Although there have been many success stories about the gluten free casein free diet in the treatment of autism, there has not been enough scientific research to prove that is does improve symptoms of autism. Without the proven facts and long term studies, consequences of the diet are currently unknown. Each child is different and has different needs. What may have worked for one child will not necessarily work for another. To date, there are no consistent guidelines in how to follow the gfcf diet. Some parents remove both gluten and casein, while others remove only one, both claiming to see the same results. This diet is still based on an unproven theory. An abundance of information on this topic can be found on the Internet, however this information is not regulated and may in fact be inaccurate.

Before starting the gfcf diet, consider doing the following: Consult a licensed physician or registered dietitian who has experience with children with special needs. Inform that practitioner that you are aware that the gfcf diet is unproven, but that you would still like to try it for your child. Ask the health care provider to give you information on how to implement the diet and avoid nutritional deficiencies. Be open to suggestions about how much time to keep your child on the diet. Be willing to develop some ways to measure changes in your child. Be willing to give up the diet if you don't see any changes. If you do continue the diet, consult your health care provider at least 
once a year to make sure that your child is continuing to meet his growth and nutrient needs. 


\section{References:}

1. Adams, JB., Holloway C. Pilot study of a moderate dose multivitamin/mineral supplement for children with autistic spectrum disorder. Journal of Alternative and Complementary Medicine. 2004; 10(6): 1033-9.

2. Ahearn, William, H. Todd Castine, Karen Nault, and Gina Green. An assessment of food acceptance in children with autism or pervasive developmental disordernot otherwise specified. Journal of Autism and Developmental Disorders 2001;31(5): 505-511.

2. Batshaw, Mark L., Paul H. Brookes, Children with Disabilities $5^{\text {th }}$ ed. Paul. H Brookes Publishing Co.2002. 370-1.

3. Bowers, L. An audit of referrals of children with autistic spectrum disorder to the dietetic service. Journal of Human Nutrition and Dietetics 2002; 15: 141-144.

4. Cornish, E. Gluten and casein free diets in autism: a study of the effects on food choices and nutrition. Journal of Human Nutrition and Dietetics. 2002; 15: 261269.

5. Dalton, Richard. Marc A. Forman, Pervasive Developmental Disorders and Childhood Psychosis. Nelson Textbook of Pediatrics $16^{\text {th }}$ ed. WB Saunders Co. 2000. 87-8.

6. Dolske MC. A preliminary trial of ascorbic acid as supplemental therapy for autism. Progr Neuropsychopharmacol Biol Psychiatry 1993; 17: 765-774.

7. Findling, R.L., K. Maxwell, L. Scotese-Wojtila, J. Huang, T. Yamashita, M. Wiznitzer. High-dose pyridoxine and magnesium administration in children with 
autistic disorder: an absence of salutary effect in a double-blind, placebocontrolled study. Journal of Autism and Developmental Disorders.1997; 27(4): 467-78.

8. Fombonne, Eric. Suniti Chakrabarti. Pervasive developmental disorders in preschool children JAMA 2001; 285(24): 3093-9.

9. Fombonne, Eric. The epidemiology of autism: a review. Psychological Medicine 1999; 29: 769-786.

10. Garvey, Josephine. Diet in autism and associated disorders. Journal of Family Health Care 2002; 12(2): 34-38.

11. Gupta, S, Aggarwal S, Heads C. Dysregulated immune system in children with autism: beneficial effects of intravenous immune globulin on autistic characteristics. Journal of Autism and Developmental Disorders 1996; 26 (4): 439-452.

12. Isherwood E. Thomas K Dietary management of Autism Spectrum Disorder- an evidence based approach. Effective Practice Bulletin 2003; 37: 1-4.

13. Kedesdy J H., Budd K.S Childhood Feeding Disorders Biobehavioral Assessment and Intervention Paul H. Brookes Publishing Co., Inc. 1998 159-191.

14. Kern, JK., Miller VS, Cauller PL, Kendall PR, Mehta PJ, Dodd M. Effectiveness of N,N-dimethylglycine in autism and pervasive developmental disorder Journal of Child Neurology. March 2001; 16(3): 169-73.

15. Kidd, Parris M. An approach to the nutritional management of autism. Alternative Therapies Sept/Oct 2003; 9(5): 22-30. 
16. Knivsberg AM, Reichelt K, Hoien T and Nodland M. A Randomised, controlled study of dietary intervention in autisitc syndromes. Nutritional Neuroscience. 2002; 5(4): 251-261.

17. Knivsberg AM, Reichelt KL, Hoien T, and Nodland M. Effect of a dietary intervention on autistic behavior. Focus on Autism and other Developmental Disabilities. 2003; 18(4): 247-256.

18. Lucarelli, S. T. Frediani, A.M. Zingoni, F. Ferruzzi, O. Giardini, F. Quintieri, M. Barbato, P.D’eufemia, and E. Cardi. Food Allergy and infantile autism Panminerva Med. 1995; 37: 137-41.

19. Levy, SE., Mandell DS., Merhar S, Ittenbach RF, Pinto-Martin JA. Use of complementary and alternative medicine among children recently diagnosed with autistic spectrum disorder. Journal of Developmental and Behavioral Pediatrics. 2003; 24(6): 418-23.

20. Mandell DS, Palmer R. Differences among states in the identification of autistic spectrum disorders. Archives of Pediatric and Adolescence Medicine. 2005; 159(3): 266-9.

21. Megson M. Is autism a G-alpha protein defect reversible with natural vitamin A? Med Hypothesis 2000; 54(6): 979-83.

22. Murch, S. Diet, immunity, and autistic spectrum disorders. Journal of Pediatrics. 2005; 146(5): 582-4.

23. Nicolson, R, Szatmari P. Genetic and neurodevelopmental influences in autistic disorder. Canadian Journal Psychiatry 2003; 48(8): 526-73. 
24. Ogletree BT, and Oren T. Application of ABA principles to general communication instruction. Focus on Autism and other Developmental Disabilities. 2001;16(2): 102-9.

25. Panksepp, J. The long-term psychobiological consequences of infant emotions: prescriptions for the twenty-first century. Infant Mental Health Journal. 2001; 22(1-2): 132-173.

26. Paulson S, Sputa CL. Patterns of Parenting during adolescence: perceptions of adolescents and parents. Adolescence. 1996; 31(122): 369-381.

27. Pavone L, Fiumara A, Bottaro G, Mazzone D, Coleman M. Autism and celiac disease: failure to validate the hypothesis that a link might exist. Biological Psychiatry. 1997; 42(1): 72-5.

28. Rimland B. Controversies in the treatment of autistic children: vitamin and drug therapy. Journal of Child Neurology. 1988; 3: S68-71.

29. Rimland B. The differentiation of childhood psychoses: an analysis of checklists for 2,218 psychotic children. Journal of Autism Childhood Schizophrenia. 1971; 1(2): $161-74$.

30. Shattock P, Whiteley P. Biochemical aspects in autism spectrum disorders: updating the opioid-excess theory and presenting new opportunities for biomedical intervention. Expert Opinion. Ther Targets 2002;6(2): 175-83.

31. Shek DTL. Adolescents perception of parental and maternal parenting styles in a Chinese context. The Journal of Psychology. 1998; 132(5): 527-537.

32. Spence SJ. The genetics of autism pediatric neurology. 2004; 11: 196-204. 
33. Tanoue Y, Oda S, Asano F, Kawashima K. Epidemiology of infantile autism in southern Ibaraki, Japan: differences in prevalence in birth cohorts. Journal of Autism and Developmental Disorders. 1988:8(2): 155-66.

34. Trevarthen C. Aitken K, Papoudi D and Robarts J. Children with Autism Diagnosis and Interventions to Meet Their Needs. Kingsley Publishers 1996; 426.

35. Wakefield AJ, Montgomery SM, Autism, viral infections and measles-mumpsrubella vaccinations. Israel Medical Association Journal. 1999;1: 1279-1290.

36. Whiteley P. Autism Unraveled conference- The Biology of Autism-Unravelled Expert Opinion. Pharmacotherapy. 2001; 2(7): 1191-1193.

37. Whitney E. Rady Rolfes S. Understanding Nutrition $8^{\text {th }}$ edition Wadsworth Publishing Company 1999. 517-8.

38. Williams M. Nutrition for Health, Fitness \& Sport $7^{\text {th }}$ edition The McGraw Hill Company 2005. 40-1.

39. William, S. Nutrition and Diet Therapy $8^{\text {th }}$ edition Mosby publishing company. 1997. 201.

40. Williams, JG, Brayne CE, Higgins JP. Systematic review of prevalence studies of autism spectrum disorders. Archives of Diseases in Childhood 2005; 29. 


\section{Appendix 1 (Parents answers to questions about the gluten free casein free diet with}

\section{their autistic children)}

This survey is completely voluntary; please feel free to skip any question that you would not feel comfortable answering.

1. How did you hear about the gluten free casein free diet?

2. What were the determining factors that made you decide to put your child on the gluten free casein free diet?

3. How long has your child been on the diet, or was on the diet?

4. What foods did you eliminate when you put your child on the diet?

Of those foods which ones does your child like?

5. Do you find it hard to maintain the diet for your child?

6. Have you noticed any behavioral changes in your child since starting the diet?

7. Do you feel that these behavioral changes (if any) are due to the diet?

8. Do you know if your child is lacking any nutrients from being on the diet?

9. What is the most difficult part of maintaining the diet?

10. Do you feel that you child is receiving a balanced diet?

11. If not, what do you feel they are lacking?

12. Do you do anything to compensate for this? (Supplements)

13. Have you consulted a physician or dietitian for help or information on this diet?

14. Has (was) your child been receiving any other therapies while he/she has been on the diet? If so which ones and for how long?

15. Before you put your child on the GFCF diet did he/she avoid any foods or food groups? If so which ones?

Would you be willing to fill out a three-day diet record for your child to be sent to me for analysis? I would need DOB (or age), weight, height, activity level and a list of medications (if any).

Activity Scale

0-1 sedentary. 2-3 walks, normal daily living. 4-5 plays. 6-7 runs and plays with others. 8-9 very active. 10 hyperactive 


\section{Appendix 2}

Dear Parent,

My name is Annette Puglisi and I am a graduate student in Human Nutrition and Foods at West Virginia University. I am also a graduate assistant at the Center for Excellence in Disabilities in Morgantown. I am currently working on my Master's thesis, which deals with autistic children that are or have been on the gluten free casein free diet.

You may have seen information either in books, on the internet, or from professional, etc about this diet. However, the effectiveness of this diet is still currently unavailable. The proper research has not been done to scientifically state whether this elimination diet can improve your child's autistic behaviors or, provide your child with the proper nutrition for growth and development. Research on this topic has been promising thus far, however do the benefits of this diet outweigh the hassles?

What I hope to accomplish through my research project is to provide you with the information needed to decide whether to keep your child on this diet. By answering a short survey and, by sending me a three-day diet history (see package) of everything your child eats while on the diet, I can provide for you a diet analysis specific to your child. With this information in hand you will be more informed to make a better decision for the proper nutrition for your child. Feel free to skip any question that you do not want to answer. Participation is voluntary, however greatly appreciated on any level. Enclosed is a self-addressed envelope, please return survey and/or diet history by February 282005.

Thank you, 
Appendix 3

\section{Autism Biomedical Information Network}

\section{DSM-IV Criteria, Pervasive Developmental Disorders} 299.00 Autistic Disorder

A. A total of six (or more) items from (1), (2), and (3), with at least two from (1), and one each from (2) and (3):

(1) qualitative impairment in social interaction, as manifested by at least two of the following:

(a) marked impairment in the use of multiple nonverbal behaviors, such as eye-to- eye gaze, facial expression, body postures, and gestures to regulate social interaction

(b) failure to develop peer relationships appropriate to developmental level

(c) a lack of spontaneous seeking to share enjoyment, interests, or achievements with other people (e.g., by a lack of showing, bringing, or pointing out objects of interest)

(d) lack of social or emotional reciprocity

(2) qualitative impairments in communication, as manifested by at least one of the following:

(a) delay in, or total lack of, the development of spoken language (not accompanied by an attempt to compensate through alternative modes of communication such as gesture or mime)

(b) in individuals with adequate speech, marked impairment in the ability to initiate or sustain a conversation with others

(c) stereotyped and repetitive use of language or idiosyncratic language

(d) lack of varied, spontaneous make-believe play or social imitative play appropriate to developmental level

(3) restricted, repetitive, and stereotyped patterns of behavior, interests, and activities as manifested by at least one of the following:

(a) encompassing preoccupation with one or more stereotyped and restricted patterns of interest that is abnormal either in intensity or focus

(b) apparently inflexible adherence to specific, nonfunctional routines or rituals

(c) stereotyped and repetitive motor mannerisms (e.g., hand or finger flapping or twisting or complex whole-body movements)

(d) persistent precoccupation with parts of objects

B. Delays or abnormal functioning in at least one of the following areas, with onset prior to age 3 years: (1) social interaction, (2) language as used in social communication, or (3) symbolic or imaginative play.

C. The disturbance is not better accounted for by Rett's disorder or childhood disintegrative disorder.

\subsection{Pervasive Developmental Disorder, Not Otherwise Specified}

This category should be used when there is a severe and pervasive impairment in the development of reciprocal social interaction or verbal and nonverbal communication skills, or when stereotyped behavior, interests, and activities are present, but the criteria are not met for a specific pervasive developmental disorder, schizophrenia, schizotypal personality disorder, or avoidant personality disorder. For example, this category includes "atypical autism" -- 
presentations that do not meet the criteria for autistic disorder because of late age of onset, atypical symptomatology, or subthreshold symptomatology, or all of these.

\subsection{Asperger's Disorder}

A. Qualitative impairment in social interaction, as manifested by at least two of the following:

(1) marked impairment in the use of multiple nonverbal behaviors, such as eye-to-eye gaze, facial expression, body postures, and gestures to regulate social interaction

(2) failure to develop peer relationships appropriate to developmental level

(3) a lack of spontaneous seeking to share enjoyment, interests, or achievements with other people (e.g., by a lack of showing, bringing, or pointing out objects of interest to other people)

(4) lack of social or emotional reciprocity

B. Restricted, repetitive, and stereotyped patterns of behavior, interests, and activities, as manifested by at least one of the following:

(1) encompassing preoccupation with one or more stereotyped and restricted patterns of interest that is abnormal either in intensity or focus

(2) apparently inflexible adherence to specific, nonfunctional routines or rituals

(3) stereotyped and repetitive motor mannerisms (e.g., hand or finger flapping or twisting, or complex whole-body movements)

(4) persistent preoccupation with parts of objects

C. The disturbance causes clinically significant impairment in social, occupational, or other important areas of functioning.

D. There is no clinically significant general delay in language (e.g., single words used by age 2 years, communicative phrases used by age 3 years).

E. There is no clinically significant delay in cognitive development or in the development of ageappropriate self-help skills, adaptive behavior (other than in social interaction), and curiosity about the environment in childhood.

F. Criteria are not met for another specific pervasive developmental disorder or schizophrenia.

\subsection{Rett's Disorder}

A. All of the following:

(1) apparently normal prenatal and perinatal development

(2) apparently normal psychomotor development through the first 5 months after birth

(3) normal head circumference at birth

B. Onset of all of the following after the period of normal development:

(1) deceleration of head growth between ages 5 and 48 months

(2) loss of previously acquired purposeful hand skills between ages 5 and 30 months with the subsequent development of stereotyped hand movements (i.e., hand-wringing or hand washing)

(3) loss of social engagement early in the course (although often social interaction develops later)

(4) appearance of poorly coordinated gait or trunk movements

(5) severely impaired expressive and receptive language development with severe psychomotor retardation 


\subsection{Childhood Disintegrative Disorder}

A. Apparently normal development for at least the first 2 years after birth as manifested by the presence of age-appropriate verbal and nonverbal communication, social relationships, play, and adaptive behavior.

B. Clinically significant loss of previously acquired skills (before age 10 years) in at least two of the following areas:

(1) expressive or receptive language

(2) social skills or adaptive behavior

(3) bowel or bladder control

(4) play

(5) motor skills

C. Abnormalities of functioning in at least two of the following areas:

(1) qualitative impairement in social interaction (e.g., impairment in nonverbal behaviors, failure to develop peer relationships, lack of social or emotional reciprocity)

(2) qualitative impairments in communication (e.g., delay or lack of spoken language, inability to initiate or sustain a conversation, stereotyped and repetitive use of language, lack of varied make-believe play)

(3) restricted, repetitive, and stereotyped patterns of behavior, interests, and activities, including motor stereotypies and mannerisms

D. The disturbance is not better accounted for by another specific pervasive developmental disorder or by schizophrenia.

\section{Diagnostic and Statistical Manual, 4th Edition, @1994, American Psychiatric Association}




\section{Vita \\ Annette Puglisi}

Nettie.Puglisi@mail.wvu.edu

Address: 769 Willowdale Rd, Morgantown, WV 26505 (304) 281-2726

\section{Education:}

\section{Professional}

\section{Experiences:}

Graduate Assistant, West Virginia University Center of Excellence and Disabilities, Morgantown, WV 26505. Responsibilities included: completing REACH home grant curriculum, attending and participating in various clinics, contributing to an interdisciplinary team, completing nutritional assessments, completing case studies related to nutritional concerns with individuals with disabilities and special health care needs.

Teaching Assistant, West Virginia University, Morgantown, WV 26506. Responsibilities included:

Grading papers, speeches, conduction mock interviews, and teaching when needed.

Dietetic Assistant, Ruby Memorial Hospital, Morgantown, WV 25606. Responsibilities included:_Caring for patients and helping order meals according to prescribed diet.

Dietetic Assistant, Wheeling Hospital, Wheeling, WV 26003. Responsibilities included: caring for patients and helping order meals according to prescribed diet. 
Work

Experiences:

Honors and Activities:
Dietitian/Food Service Manager West Virginia University, Morgantown, WV 26505. Responsibilities included: Providing nutritional information for all menu items served in the dining halls, Hosting nutrition focus groups, Developing a program to teach student to choose healthier foods entitled "Healthy U", providing individual counseling on an as needed basis, providing educational lectures on each floor, provide in services for food service workers on food allergies.

Server, GlassHouse Grille, Morgantown, WV, 26505.

Responsibilities included: Waiting tables and working banquets. Sept 2002-present

Server, Wheeling Country Club, Wheeling, WV 26003. Responsibilities included: Waiting table, bartending, and working banquets, weddings and parties. May 1999-January 2002

West Virginia University, Morgantown, WV.

Invited Honorary:

- National Society of Collegiate Scholars

- Golden Key

- Phi Upsilon Omicron. (Induction Chair)

- Gamma Beta Phi

Awards received:

- Academic Achievement Award (Freshman Year)

-Academic Achievement Award (Soph Year)

- Sarah Protzman-Arbuckle Scholarship (Soph, Jr, and Sr year)

- West Virginia University Delegate for National Phi Upsilon Omicron Conclave

- Davis College of Agriculture, Forestry, and Consumer Science's 2003 feature student.

- Graduated Cum Laude

Organizations:

-President Elect for Mountaineer District Dietetic Association

- Student Dietetic Association (Vice President)

- American Dietetic Association

- Newman Center Volunteer

- St. John's Youth Group Leader

- World AIDS Day Volunteer

- Habitat for Humanity Volunteer

- Circle of Friends Volunteer

- Intramural Sports (Basketball, Volleyball, Bowling).

- Regional representatives for the National intramural basketball tournament 